Transportation Research Forum

Quantification of the Accuracy of Low Priced GPS Receivers for Crash Location Author(s): Thobias Sando, Renatus Mussa, John Sobanjo, and Lisa Spainhour

Source: Journal of the Transportation Research Forum, Vol. 44, No. 2 (Summer 2005), pp. 19-32

Published by: Transportation Research Forum

Stable URL: http://www.trforum.org/journal

The Transportation Research Forum, founded in 1958, is an independent, nonprofit organization of transportation professionals who conduct, use, and benefit from research. Its purpose is to provide an impartial meeting ground for carriers, shippers, government officials, consultants, university researchers, suppliers, and others seeking exchange of information and ideas related to both passenger and freight transportation. More information on the Transportation Research Forum can be found on the Web at www.trforum.org. 


\section{QUANTIFICATION OF THE ACCURACY OF LOW PRICED GPS RECEIVERS FOR CRASH LOCATION}

Global positioning system (GPS) has been identified as a potential tool for capturing crash location data. This study quantifies factors that could affect the accuracy of GPS receivers. The results showed that GPS receiver orientation, site obstructions, and weather have significant effects on the accuracy of GPS receivers. Time of day and number of satellites were not found to significantly affect the accuracy of GPS receivers. HDOP values of 1.2 or less were found to be adequate for crash location purposes. An accuracy improvement of $20.7 \%$ was realized by filtering GPS data based on HDOP values.

\section{by Thobias Sando, Renatus Mussa, John Sobanjo, and Lisa Spainhour}

\section{INTRODUCTION}

The Global positioning system (GPS) provides the most ubiquitous and reliable capability of locating features on the surface of the earth. GPS is a satellite-based navigation system developed by the U.S. Department of Defense in the early 1970s. The system provides accurate, continuous, worldwide, three-dimensional position information to users with appropriate receiving equipment. GPS uses a constellation of 24 satellites providing precise position and time data to users around the world. The satellites are continuously monitored by ground stations located worldwide and transmit signals that can be detected by anyone with a GPS receiver anywhere. GPS has been applied in a wide range of scientific fields including topography, geodesy, hydrography, photogrammetry, and transportation. In the field of transportation, GPS is now being used to locate highway crashes. In the past, there was some reluctance by transportation officials to use GPS for crash location because of poor accuracy.

This study was conducted to investigate the usability of GPS receivers by police officers in reporting crash location on the crash reports to enhance accurate crash analysis. In Florida's current practice, the location of a crash is reported by an officer using one of the following methods: (1) estimation of the distance from a known reference point, (2) measuring the distance from a reference point using the car mileage, (3) measuring the distance from the reference point using a tape measure, and (4) measuring the distance from the reference point using an odometer. Of the above methods, the first is the one most used by police officers. The officer would estimate the distance of the crash from a known reference point, normally the nearest intersection. Clearly, the estimation is subject to error and may vary significantly from one officer to another. The further the crash is from the intersection, the larger the location estimation error is expected to be. The current method also causes non-uniformity in reporting the location of the crash. Most jurisdictions do not have a standard method of reporting crash location. The level of details of the crash location would depend on the jurisdiction and the reporting officer among other factors. At a minimum, the officer would report the street name and the distance from a known location, usually the nearest intersection. However, a street might have more than one name - local name, state highway number and federal number for the same street, the same location would be reported differently by different officers.

Contrary to the current practice, global positioning system (GPS) uses a constellation of 24 satellites providing precise position and time data to users around the world. The satellites are continuously monitored by ground stations located worldwide and transmit signals that can 
be detected by anyone with a GPS receiver. GPS technology has a potential of improving crash location data, and hence enhance accurate spatial analysis of crashes. The use of GPS eliminates the need to estimate the crash location. GPS reports the crash location in terms of latitude and longitude (GPS coordinates). The use of GPS coordinates provides an efficient way of performing spatial crash analyses using geographic information systems (GIS) software packages. The location information provided by GPS could be used in GIS to locate crashes on a map and perform various spatial analyses in GIS environment. Examples of GIS analyses that can be facilitated by the location information provided by GPS are shown in Table 1 . These analyses could be used to identify hazardous locations and help in the decision-making process regarding appropriate corrective measures. GPS also helps provide a permanent crash location (latitude/longitude) as other forms of location information such as street names could be changed with time. Note that GPS does not eliminate street names in crash reports but enhances crash location data by adding latitude and longitude information.

Accurate location of a highway crash is of paramount importance. This is because a highway occupies a relatively narrow space, in which travel lanes are generally 12 feet. If a crash were to be located inaccurately, the crash might be shown to have occurred in a wrong lane which could be an opposing lane or an adjacent lane. Crashes that occur at intersections and interchanges need even more accuracy in GPS readings to avoid coding a left-turn crash as a through crash or an on-ramp crash as an off-ramp crash. The implications of inaccurate location of highway crashes could be wrong prioritization of hazardous locations and instituting wrong corrective measures to safety problems. Thus, the importance of getting accurate GPS readings for crash location cannot be overemphasized.

Following the removal of selective availability and improvement of GPS receiver technology, GPS now offers a significant

\section{Table 1: GIS Analyses That Can Be Facilitated by GPS Data}

\begin{tabular}{|l|l|}
\hline Analysis Type & Description \\
\hline Intersection/spot & $\begin{array}{l}\text { GIS analysis of specific points of interest, such as intersections in the } \\
\text { road network. }\end{array}$ \\
\hline Segment & $\begin{array}{l}\text { GIS analysis of the roadway segments, such as streets connecting inter- } \\
\text { sections. }\end{array}$ \\
\hline Corridor & $\begin{array}{l}\text { Corridor analysis differs from segment analysis because it considers } \\
\text { crashes occurring along the whole corridor, such as crash analysis along } \\
\text { I-75. The corridor analysis method provides means to visually locate } \\
\text { high crash concentrations within a corridor. }\end{array}$ \\
\hline Area & $\begin{array}{l}\text { GIS analysis by which the densities of crashes are mapped to determine } \\
\text { the distribution density of crashes per area or per length. }\end{array}$ \\
\hline Pattern & $\begin{array}{l}\text { GIS analysis based on various area divisions such as zip codes, cen- } \\
\text { sus tracts, counties, districts, zones, etc. The area analysis is used for } \\
\text { identification of critical zones or neighborhoods where different traffic } \\
\text { safety problems exist. }\end{array}$ \\
\hline Proximity & $\begin{array}{l}\text { GIS analysis used to examine the change of crash rates with the change } \\
\text { of other factors including land use, population, and highway functional } \\
\text { class. }\end{array}$ \\
\hline Cluster & $\begin{array}{l}\text { GIS analysis to evaluate crashes occurring within a certain distance from } \\
\text { specific locations such as schools, shopping centers, etc. }\end{array}$ \\
\hline & $\begin{array}{l}\text { GIS method used to study crashes clustered around a specific roadway } \\
\text { feature, such as a bridge or railroad crossing. }\end{array}$ \\
\hline
\end{tabular}


opportunity of improving coding of crashes in a crash form with GPS readings. The improvement in locational accuracy starts with how the investigating police officers use the GPS receiver to capture the latitude and longitude readings. The purpose of this study was to quantify factors that could affect the ability of a police officer to collect and record accurate GPS readings on a crash form. This research is part of a project being sponsored by the State Safety Office of the Florida Department of Transportation. The project is aimed at promoting the use of electronic crash forms by police agencies for recording crash and citation information in the field.

\section{REVIEW OF PREVIOUS STUDIES}

A study conducted by Lechner and Baumann (2000) discussed the main factors that significantly contributed_to the accuracy of GPS readings. These included the geometric position of the satellites (PDOP), the clock errors of the satellites, the ephemeris errors (errors in the transmitted location of the satellite), the tropospheric errors (errors caused by signal delay as they pass through the lowest part of the earth's atmosphere - troposphere), ionospheric errors (errors caused by signal delay as they pass through the uppermost part of the earth's atmosphere - ionosphere), and the multipath effects (errors caused by reflected signals entering the receiver antenna). Other significant factors were the inaccuracies of the receiver, and the artificial deterioration of clock and ephemeris data for civil users by the U.S. Department of Defense - what was known as selective availability (SA). It should be noted that the study by Lechner and Baumann was conducted prior to removal of the selective availability by the federal government in May 2000.

Since the rescinding of selective availability, a number of studies have been conducted to measure the improvement of GPS accuracy and the performance of various GPS receivers. Graettinger et al. (2000), just after the removal of SA, evaluated inexpensive GPS receivers used for crash location. The study reported approximately a 10-fold accuracy improvement after removal of selective availability. It was notable that the observed accuracies were considerably higher than the reported manufacturers' accuracies. Sando et al. (2004) also reported significant accuracy improvements since the removal of SA. The study indicated significant accuracy improvements compared to the Graettinger et al. (2001) study in a period of three years. A more recent study by Green and Agent (2004) showed that WAAS-corrected GPS receivers are capable of obtaining accurate latitude and longitude data at a crash site that would allow the site to be properly located.

\section{RESEARCH DESIGN}

Accuracy is the measure of the closeness of the observations to the true value. Survey markers have previously been used for evaluation of the accuracy of GPS receivers that are used for crash location (Graettinger et al., 2001). A survey marker is a physical point with known coordinates referenced from the datum established by surveyors using high-precision surveyor instruments. Survey markers are established using high-precision survey instruments to the accuracy of sub-decimeter (manufacturer reported accuracy of less than a decimeter). Survey markers maintained by the Florida Department of Transportation (FDOT) were used in this study. Twenty-nine sites located in nine counties in northwest Florida were identified. The markers were carefully sampled to include different site characteristics, e.g., close to a building, close to trees, and open space. The markers were sampled to represent a wide area of northwest Florida.

Many brands of GPS receivers are being produced because of the increased use of GPS in recreational activities and navigational purposes. Two major producers of GPS receivers, GARMIN International Inc. and MagellanGPS produce more than 10 and 30 different types of GPS receivers, respectively. The literature review revealed that all GPS receivers can be categorized in three main configurations, namely autonomous, wide area augmented system (WAAS), and continuously operating reference station (CORS). The autonomous configuration uses a single receiver and at least three satellites to instantaneously determine location. It is the simplest mode and does not require any post- 
processing or additional equipment. On the other hand, WAAS is a correction service that uses both land-based control stations and geostationary satellites for adjusting the GPS readings to improve positional accuracy. The technology significantly improved handheld receivers that, for no additional fee, the accuracy of three meters or less can be attained. The system was developed originally for military use, but is now available to civilians. Currently the WAAS system is not fully operational. There are two WAAS satellites in place over the Pacific and Atlantic Oceans. In the United States, the CORS network provides high-accuracy correction information for postprocessing and real-time, and is available over the Internet for free.

In the beginning of this study, a survey was done to determine which GPS receivers are used for crash location in different states. It was found that most agencies used WAAS-corrected GPS receivers, mainly Meridian and Garmin products, to capture crash location. In this study, four GPS receivers were selected to investigate the best GPS receiver for crash location. The selection was based on the GPS configuration and the most-used GPS receivers in crash location in other states. Three main configurations were identified, AUTONOMOUS, WAAS and CORS. The units that were used are Pharos (autonomous), Magellan Meridian and Garmin 76S (WAAS corrected), and Trimble Geoexplorer (CORS corrrected). Data were collected from established survey markers in seven counties in the northern part of Florida. The counties were Escambia, Okaloosa, Washington, Jackson, Holmes, Gadsden and Leon.
Data were collected in two stages. The first stage of data collection was for recommending the best GPS receiver while the second stage was for analyzing the influences of different factors on GPS accuracy. In the first stage, a single final reading (batch reading) was recorded for each unit after the GPS receiver was turned on for four minutes. For each site, data were collected at three different times of the day - morning, afternoon, and evening. In the second stage, a stream of data was collected instead of batch data. A code was written in the Visual Basic programming language to capture data of interest which included time, latitude, longitude, number of satellites, PDOP (position dilution of precision), and HDOP (horizontal dilution of precision).

\section{PROCEDURE}

The procedure used in the research is shown in Figure 1 and discussed in the following sections.

\section{Summarize the Data in a Spreadsheet Format}

The data collected in the field were summarized in a Microsoft Excel spreadsheet. The columns of the spreadsheet data included site code, latitude/ longitude readings, the time the readings were taken, the number of satellites used to record the readings, and the amount of time it took to lock the satellites.

\section{Figure 1: Data Processing Procedure}

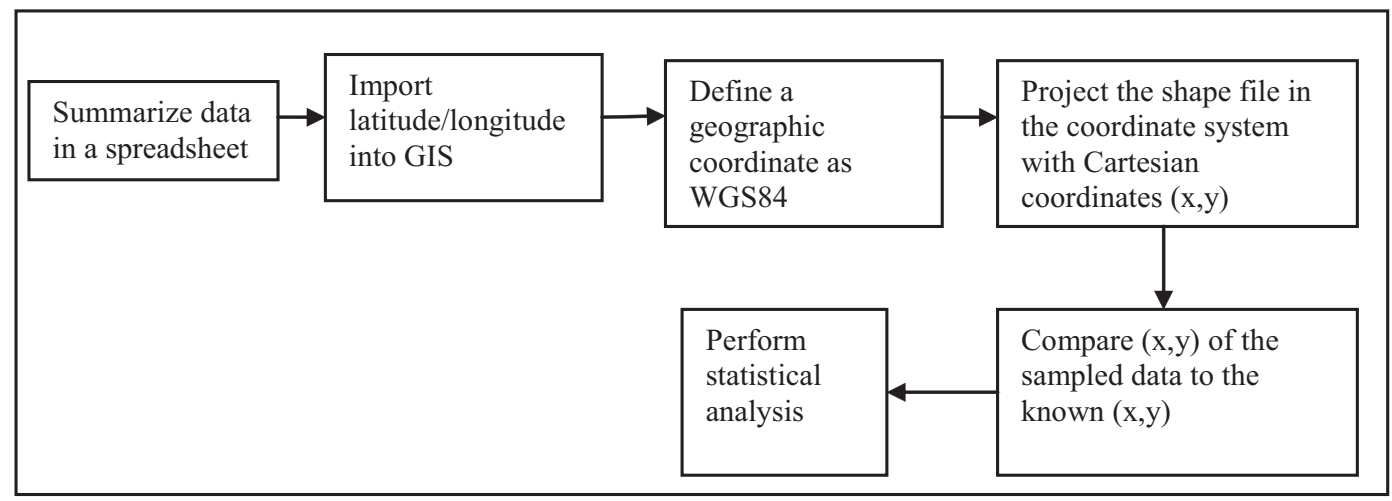




\section{Create Shape File of Data Points}

The latitude and longitude information was imported in GIS to create a shape file. A shape file is a non-topological digital storage format for storing the geometric location_of features on the map and their associated attribute information. The creation of a shape file for GPS coordinates enabled easy maneuverability of GPS data from one coordinate system to another. Coordinate transformation was necessary to obtain the GPS data in Cartesian coordinates which are in linear measurements instead of latitude/longitude which are in degree measurements. Note that accuracy of GPS is recorded in unit length (e.g., feet) and not degrees.

\section{Convert to State Plane Coordinate System}

The ArcGIS software package was used for processing original data (latitude/longitude) into state plane coordinates. The latitude and longitude coordinate system is defined in GIS as World Geodetic System 1984 (WGS84). The coordinate system projection tool embedded in arcToolbox (GIS processing tool in ArcGIS package) was used to convert the shape file from the WGS 84 coordinate system to the North Florida state plane coordinate system. Conversion was necessary to obtain the Cartesian coordinates that could be used to compute the accuracy of the GPS data in linear measurements.

\section{Create $x$ and $y$ Attributes}

The coordinates of features of the GIS shape files are not generally included in the attribute table. Although one can click on the point feature and view the coordinates of each point, something needed to be done to record the coordinates of each point feature (recorded GPS coordinates) in the attribute table. The Visual Basic program was used to automate the creation of the $x$ and $y$ coordinates from the projected shape file. The program automatically generated the $x$ and $y$ coordinates of the shape file in the attribute tables. The generated $x$ and $y$ coordinates were compared with the known coordinates from the survey markers to determine the accuracy of the GPS readings.

\section{Accuracy Check}

The accuracy of each data point was computed by comparing the latitude/longitude GPS reading for the marker with known coordinates of the survey marker. The accuracy was computed using the State Plane Coordinate System for North Florida. The North Florida State Plane Coordinate System covers areas of Florida between $29^{\circ} 35^{\prime}$ and $30^{\circ} 45^{\prime}$ latitudes in the southern and northern parallels respectively. All sites that were considered in this study are within this range of latitudes. The accuracy was computed using the following equation:

(1) Accuracy $=\sqrt{\left(x_{i}-x_{0}\right)^{2}+\left(y_{i}-y_{0}\right)^{2}}$

where $x_{i}$ is the horizontal Cartesian coordinate of the GPS reading, $x_{o}$ is the known horizontal Cartesian coordinate, $y_{i}$ is the vertical Cartesian coordinate of the GPS reading, and $y_{o}$ is the known vertical Cartesian coordinate.

\section{DATA ANALYSIS}

\section{Determination of the Appropriate GPS Receiver for Crash Data Collection}

The observed accuracies of the four GPS receivers are shown in Table 2 . The results show Trimble Geoexplorer receiver, which is WAAS and CORS corrected, was the most accurate units among the four receivers tested. Its average accuracy was calculated as 5.58 feet. The Pharos receiver was found to be the least accurate with an average of 18.77 feet difference between its reading and known survey marker coordinates. The WAAS-corrected GPS receivers, i.e. Magellan Meridian receiver and Garmin $76 \mathrm{~S}$ receiver, were found to have an average accuracy of 14.17 feet. Note that, at the time of the purchase of the tested receivers in March 2003, the price of the Pharos receiver was less than $\$ 150$ while the price of the Trimble Geoexplorer receiver was approximately $\$ 6,000$. The price of the Magellan Meridian receiver and Garmin 76S receivers were less than $\$ 350$ each. The price of the Trimble Geoexplorer was considerably higher than other units because of its capabilities of post-processing and being both 
Table 2: A Summary of the Results of GPS Accuracies

\begin{tabular}{|l|c|c|r|r|}
\hline Type of receiver & $\begin{array}{c}\text { Mean } \\
\text { (feet) }\end{array}$ & $\begin{array}{c}\text { Standard } \\
\text { Deviation } \\
\text { (feet) }\end{array}$ & Range (feet) & \multicolumn{1}{c|}{$\begin{array}{c}\text { 95\% confidence } \\
\text { interval }\end{array}$} \\
\hline Pharos & 18.77 & 10.49 & 3.94 to 41.37 & 14.63 to 22.93 \\
\hline Magellan Meridian & 14.17 & 6.04 & 2.46 to 27.66 & 11.91 to 16.44 \\
\hline Garmin 76S & 12.47 & 8.17 & 2.46 to 33.86 & 9.42 to 15.52 \\
\hline Trimble Geoexplorer & 5.58 & 2.53 & 0.79 to 10.01 & 4.49 to 6.66 \\
\hline
\end{tabular}

WAAS and CORS enabled. The other receivers do not have post-processing capabilities. Postprocessing capabilities refers to the ability of the GPS receiver to store GPS system data in a format that can be used to compute differential corrections of the location data using corrections recorded at a reference receiver to improve locational accuracy.

\section{Comparison with the Previous Studies}

A previous study conducted by Graettinger in 2000 tested receivers, some of which were similar to receivers tested in the current study. A Rand McNally Street Finder Deluxe receiver (manufactured by Rand McNally) tested in 2000 had a comparable cost to the current Pharos receiver $(\$ 150)$ but was $24 \%$ less accurate. The current Garmin 76S receiver was 53.6\% more accurate than the Garmin GPS 12 Map receiver. Both of those receivers are manufactured by GARMIN International, Inc.

\section{ANALYSIS OF INFLUENCING FACTORS}

Highway crashes occur under different site conditions. While some crashes occur on roadway segments near tall buildings, some occur on the roadway site under tall trees, and some under the open sky. Highway crashes also occur at different times of the day and in different weather conditions. The following sections discuss the influence of different factors on the accuracy of GPS receivers. The influence of horizontal dilution of precision (HDOP) in the accuracy of GPS receivers is also discussed.

\section{Time of the Day}

Time-of-the-day analysis is shown in Figure 2. The figure is divided in two main portions, with each portion representing data collected on a separate day. The first portion of the graph shows data collected with the GPS positioned horizontally (9:45 am to 5:00 pm) while the second portion presents the data collected with GPS positioned vertically (10:05 am to 4:55 pm). No specific trend can be seen from the graph. However, the graph suggests that there is a clear difference between the first and second portion of the graph. This is due to the variation of accuracy caused by GPS orientation. The graph also shows that the data collected at the site with tree canopy were found to be the least accurate. Extreme peaks can be observed from the data collected from the site with tree canopy. The following sections discuss the factors which might cause the differences in accuracies depicted in Figure 2.

\section{GPS Receiver Orientation}

According to the user's manual, for effective signal reception, the Garmin GPSMAP 76S receiver must be oriented so the top of the unit points toward the sky (Garmin, 2002). If the unit is held with the top of the unit pointed toward the horizon, satellite reception may be severely degraded. The manufacturer did not mention the extent of accuracy degradation that might be caused by orienting the GPS receiver horizontally. Note, however, that most GPS users orient the GPS units horizontally because the GPS can easily sit by itself by placing it horizontally and it is easy to read GPS measurements when the unit is horizontal. 
Figure 2: Accuracy of Results by Time of Day

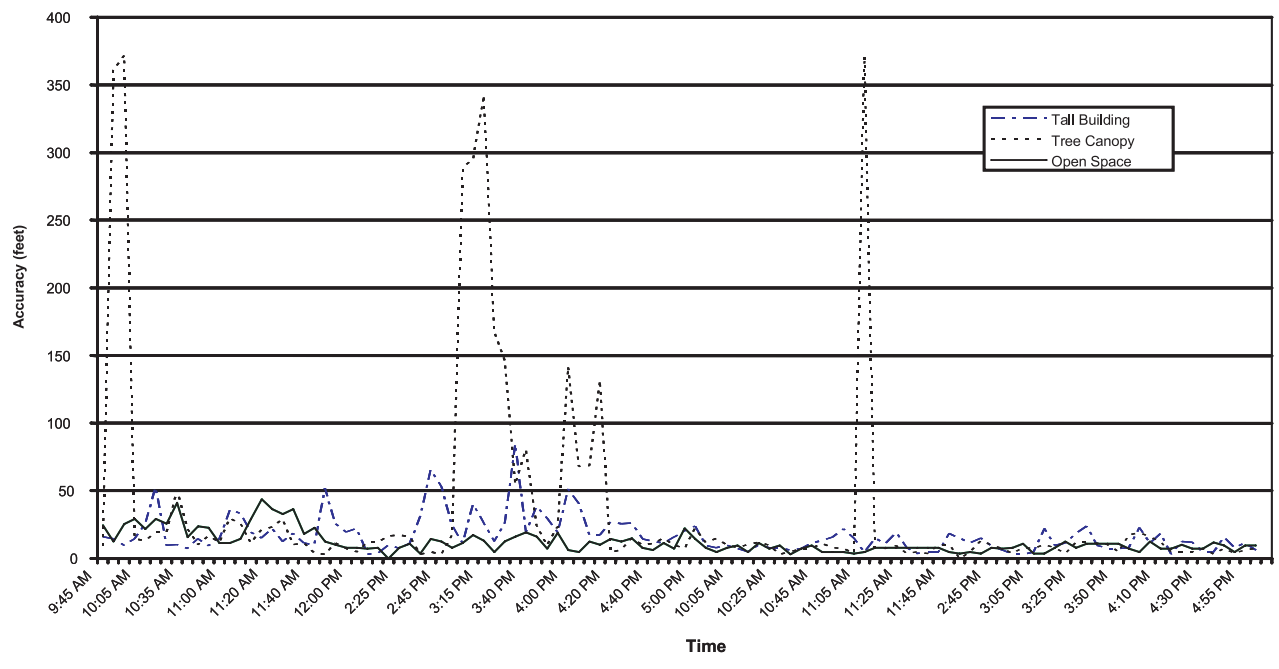

The results of the analysis of variance (ANOVA) performed to test the accuracy difference between horizontal and vertical orientation are shown in Table 3. The null hypothesis tested was that the accuracy of the GPS receiver is not significantly affected by orientation of the GPS receiver. The results yielded an F-statistic of 29.13 (near a tall building), 7.68 (under the tree canopy) and 39.01 (at the open space). All tests were significant at 5\% significance level. These results seem to suggest that the accuracy of the Garmin $76 \mathrm{~S}$ is significantly reduced by horizontal orientation of the GPS receiver. This might be due to degradation of the satellite reception.

\section{Site Obstructions}

GPS receivers require a line of sight to the satellites to obtain a signal. Any object in the path of the signal has the potential to interfere with the reception of the GPS signal. Site obstructions are critical to GPS coordinates accuracy. A site located near or under a tree canopy may provide a low accuracy as compared to the site located in the open field because the satellites are blocked

Table 3: Results of ANOVA Test for Orientation

\begin{tabular}{|l|l|c|c|c|c|c|}
\hline $\begin{array}{l}\text { Primary } \\
\text { Effect }\end{array}$ & Orientation & $\begin{array}{c}\text { Sample } \\
\text { Size }\end{array}$ & $\begin{array}{c}\text { Mean } \\
\text { (feet) }\end{array}$ & $\begin{array}{c}\text { Std. } \\
\text { Dev. }\end{array}$ & F-Value & $\begin{array}{c}\text { Significance } \\
\text { of } \mathbf{F}\end{array}$ \\
\hline \multirow{2}{*}{$\begin{array}{l}\text { Tall } \\
\text { Building }\end{array}$} & Horizontal & 57 & 23.0 & 15.9 & \multirow{2}{*}{29.13} & 0.000 \\
\cline { 2 - 5 } & Vertical & 53 & 10.61 & 5.51 & \multirow{2}{*}{7.68} & \multirow{2}{*}{0.007} \\
\hline \multirow{2}{*}{$\begin{array}{l}\text { Tree } \\
\text { Canopy }\end{array}$} & Horizontal & 57 & 55.4 & 94.4 & \\
\cline { 2 - 5 } Open Space & Vertical & 53 & 15.0 & 50.0 & \multirow{2}{*}{39.01} & 0.000 \\
\cline { 2 - 5 } & Horizontal & 57 & 16.19 & 9.72 & \\
\hline
\end{tabular}


by the tree canopy. The same applies to sites located close to tall buildings.

Three survey markers placed in different site conditions were identified. Survey marker $55-01-\mathrm{F} 20 \mathrm{H}$ is located in open space with no obstruction while survey marker $55-00-\mathrm{C} 10 \mathrm{H}$ and "Ginger Wetherell" are located near a tree canopy and tall building respectively.

Data were collected by three different observers at the same time in the three sites to enable statistical comparison of paired data. A paired t-test was performed to analyze the effects of obstructions such as tree canopies and tall buildings on GPS accuracy. The null hypothesis that the data collected at different sites at the same time have the same accuracy versus the alternative hypothesis that site obstructions have significant effects on GPS accuracy was tested. The results presented in Table 4 suggest a significant difference between the data collected at each of the three sites at 0.05 level of significance. $P$-values were much smaller than the 0.05 significance level. The $p$ values of 0.013 (tall building vs. tree canopy), 0.001 (tall building vs. open space), and 0.002 (tree canopy vs. open space) were obtained. The results also show that the tree canopy has a more severe effect than a tall building on GPS accuracy. This may be because the survey marker was nearer to the tree (approximately 30 feet) than the surveyor marker was to the tall building (approximately 100 feet).

\section{Number of Satellites}

GPS uses the triangulation method to locate a point on earth. A GPS receiver must be locked on to the signal of at least three satellites to calculate a $2 \mathrm{D}$ position (latitude and longitude).
One would expect the accuracy of GPS to be improved with the number of satellites locked. The results of the analysis of variance (ANOVA) did not indicate a significant effect of the number of satellites on the accuracy of the Garmin 76S GPS receiver at 95\% confidence level (Table 5). It is possible more satellites at lower elevations are locked when the number of satellites locked is high. Satellites at low elevations generally contribute to an increase in the strength of multipath interference because of the reduction in the angle of reflection - an angle at which GPS signals are reflected from the satellites (Lemmon and Gerdan, 1999). Note, however, that for the site located in an open space, the accuracy was improved with the increase in the number of satellites locked, but the difference was not statistically significant.

\section{Weather Analysis}

Weather is one of the factors known to affect GPS performance. Because signals are obtained from satellites, a clear sky day would be expected to have stronger signals than a cloudy day. The data were collected on a rainy (cloudy) day and sunny (clear sky) day at an open sky site. The GPS receiver was randomly oriented in vertical and horizontal positions.

Table 6 shows the results of the analysis of variance (ANOVA) performed to test the difference between the accuracy of GPS data collected during a sunny day (clear sky) and rainy day (cloudy sky). The analysis yielded F-values of 4.24 and 4.46 for data collected with a GPS receiver positioned vertically and horizontally respectively. The F-values of 4.24 and 4.46 correspond to p-values of 0.045 and 0.041 , respectively which indicates

Table 4: Site Conditions Analysis-Paired t-test Results

\begin{tabular}{|l|c|c|c|c|c|}
\hline Obstruction & $\begin{array}{c}\text { Mean of the } \\
\text { difference (feet) }\end{array}$ & $\begin{array}{c}\text { Standard Deviation of } \\
\text { the difference (feet) }\end{array}$ & T-value & p-value & $\begin{array}{c}\text { Reject } \\
\text { Null? }\end{array}$ \\
\hline $\begin{array}{l}\text { Tree Canopy vs } \\
\text { Tall Building }\end{array}$ & 18.87 & 78.57 & 2.52 & 0.013 & Yes \\
\hline $\begin{array}{l}\text { Tall Building vs } \\
\text { Open Space }\end{array}$ & 5.00 & 14.77 & 3.55 & 0.001 & Yes \\
\hline $\begin{array}{l}\text { Tree Canopy vs } \\
\text { Open Space }\end{array}$ & 23.87 & 78.42 & 3.19 & 0.002 & Yes \\
\hline
\end{tabular}


Table 5: Results of ANOVA Test for Number of Satellites

\begin{tabular}{|l|l|c|c|c|}
\hline Primary Effect & Orientation & Sample Size & F -value & P-value \\
\hline \multirow{3}{*}{ Tall Building } & Vertical & 57 & 0.31 & 0.902 \\
\cline { 2 - 5 } & Horizontal & 53 & 1.38 & 0.260 \\
\hline \multirow{3}{*}{ Tree Canopy } & Vertical & 57 & 0.582 & 0.660 \\
\cline { 2 - 5 } & Horizontal & 53 & 2.430 & 0.480 \\
\hline \multirow{3}{*}{ Open Space } & Vertical & 57 & 1.640 & 0.167 \\
\cline { 2 - 5 } & Horizontal & 53 & 0.88 & 0.503 \\
\hline
\end{tabular}

a significant effect of weather on the accuracy of GPS receiver. The results also indicate $33.9 \%$ and $37.0 \%$ mean accuracy differences between sunny and rainy weather for vertical and horizontal orientations, respectively. It is interesting to note that the results indicate higher accuracies for vertical orientation than horizontal orientation for both weather cases (sunny and rainy day). This confirms the results of the GPS receiver orientation analysis shown in Table 3 which indicate that for better results, the Garmin 76 GPS receiver should be vertically oriented.

\section{Time Analysis}

The optimal time for recording the GPS coordinates for high accuracy was investigated. A stream of GPS data was collected for 10 minutes, then the GPS receiver was set in an off position and switched on again to start recording another set of stream data. The first data point collected yielded the maximum accuracy error of 62 feet. The error was reduced with time as shown in the first part of Figure 3. GPS error started to level off at 4 feet from 2.3 minutes to 10 minutes when the GPS receiver was turned off. It is interesting to note that the second set of readings behaved like the last part of the first set. Figures 3 and 4 show the accuracy errors for the first and the second sets of data respectively. The results suggest the optimal time of three minutes for adequate accuracy.

\section{Horizontal Dilution}

Dilution of precision (DOP) is a unitless quantity used to measure the quality expected from a position measurement of the GPS receiver. Several DOP parameters include position dilution of precision (PDOP), horizontal dilution of precision (HDOP), vertical dilution of precision (VDOP), and time dilution of precision (TDOP). The horizontal dilution of precision (HDOP) represents the satellite geometry effect on the horizontal component of the positioning accuracy. Since the location information needed for crash report is horizontal position, HDOP is the most important parameter for determining the accuracy of the GPS receiver. The results indicate that the higher the value of HDOP, the lower the accuracy (Figure 4). Assuming the adequate accuracy of 20 feet, HDOP less or equal to 1.2 would be sufficient.

Table 6: Mean Accuracies (feet) for Rainy and Sunny Weather

\begin{tabular}{|l|c|c|c|c|c|}
\hline GPS orientation & Rainy day & Sunny day & F-value & p-value & $\begin{array}{c}\text { \% accuracy } \\
\text { change }\end{array}$ \\
\hline Vertical & 14.68 & 10.96 & 4.24 & 0.045 & $33.9 \%$ \\
\hline Horizontal & 25.70 & 18.76 & 4.46 & 0.041 & $37.0 \%$ \\
\hline
\end{tabular}


Figure 3: Accuracy Error Variation by Time - First Set

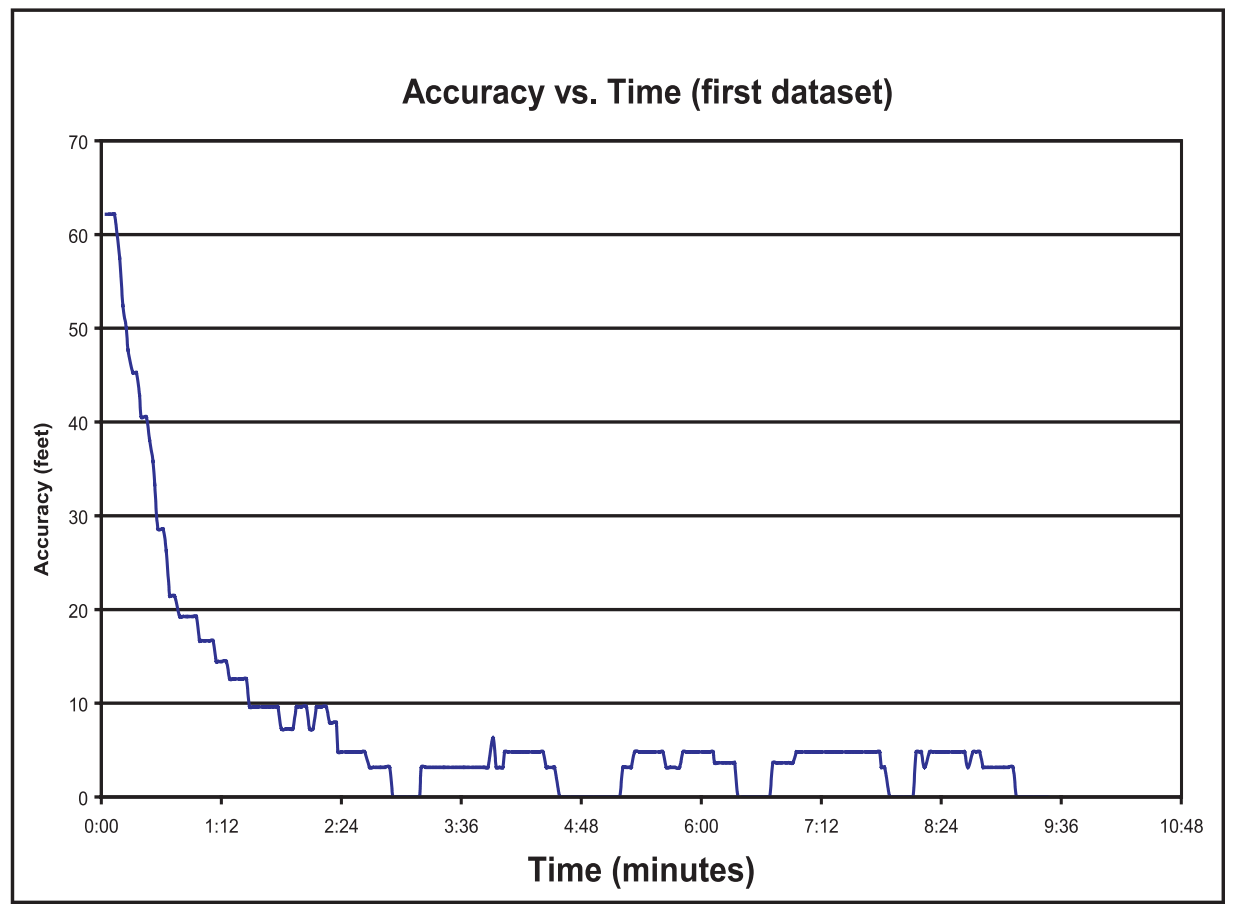

Figure 4: Accuracy Error Variation by Time - Second Set

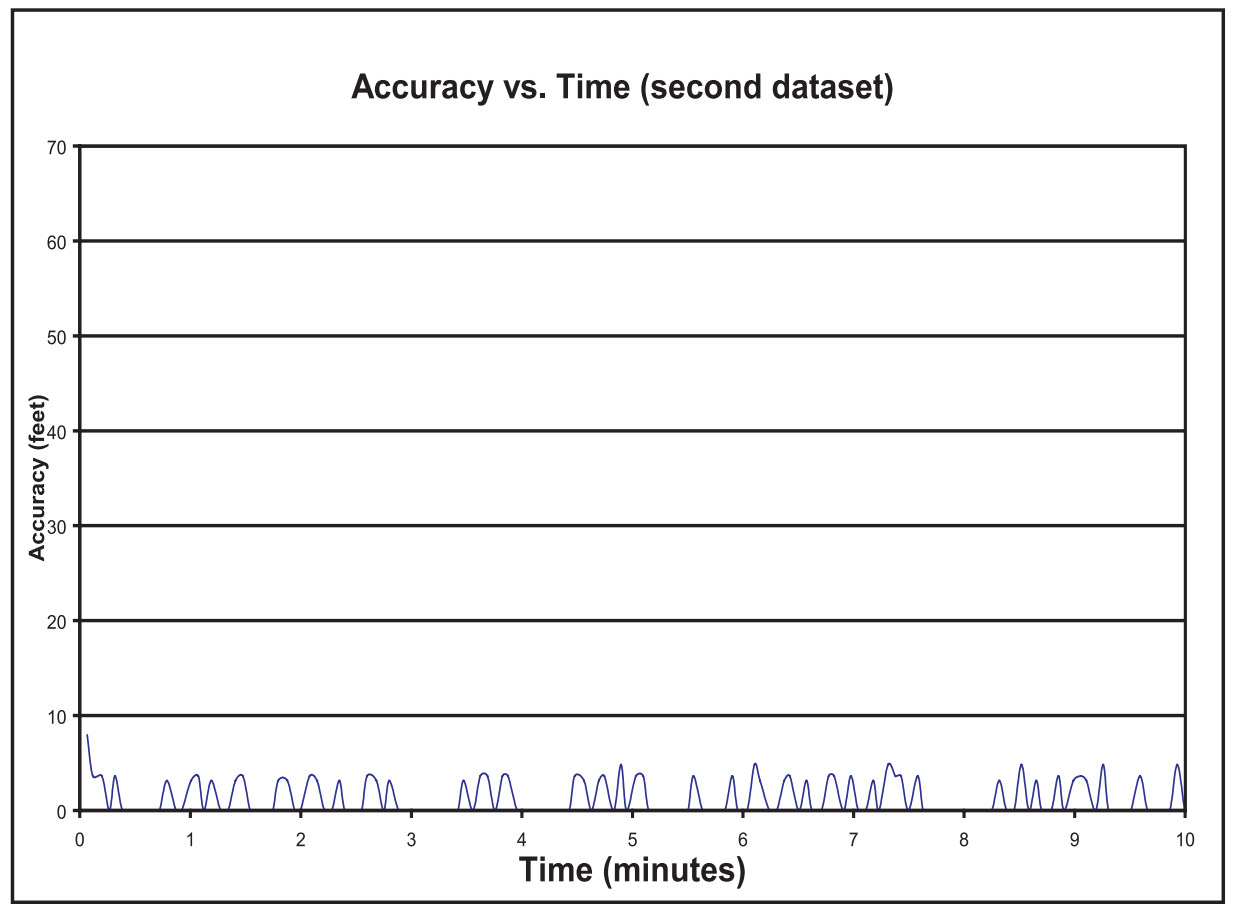




\section{Data Filtering to Improve Accuracy}

To improve the quality of GPS readings, a method to compute the weighted average of GPS readings based on Horizontal Dilution of Precision (HDOP) was developed. The data suggest that the accuracy is improved with lower values of HDOP (Figure 5). The following formula was therefore used to compute weighted average of the stream of data collected for the Garmin 76S unit:

(2) Longitude $_{\text {weighed }}=\sum_{i}^{n} \frac{1}{\operatorname{HDOP}_{i}}$ longitude $_{i}$ and,

(3) Latitude $_{\text {weighted }}=\sum_{i}^{n} \frac{1}{\text { HDOP }_{i}}$ latitude $_{i}$
Figure 6 shows the resulting weighted average graph of the filtered data against the raw data. The data were collected at an open space site on a clear day with GPS oriented vertically. The weighted average line represents the weighted average data of the stream of data collected from time $=0$ seconds to anytime $t$. The graph indicates a maximum error of 5 feet versus a maximum of about 8 feet for weighted average and raw data, respectively. The results summarized in Table 7 indicate the overall accuracy improvement of $20.7 \%$. The computed $95 \%$ confidence interval was $4.68 \mathrm{ft}$. to $5.28 \mathrm{ft}$. and $3.79 \mathrm{ft}$. to 4.08 $\mathrm{ft}$. for raw data and weighted average data.

\section{Figure 5: Variation of GPS Error by HDOP}

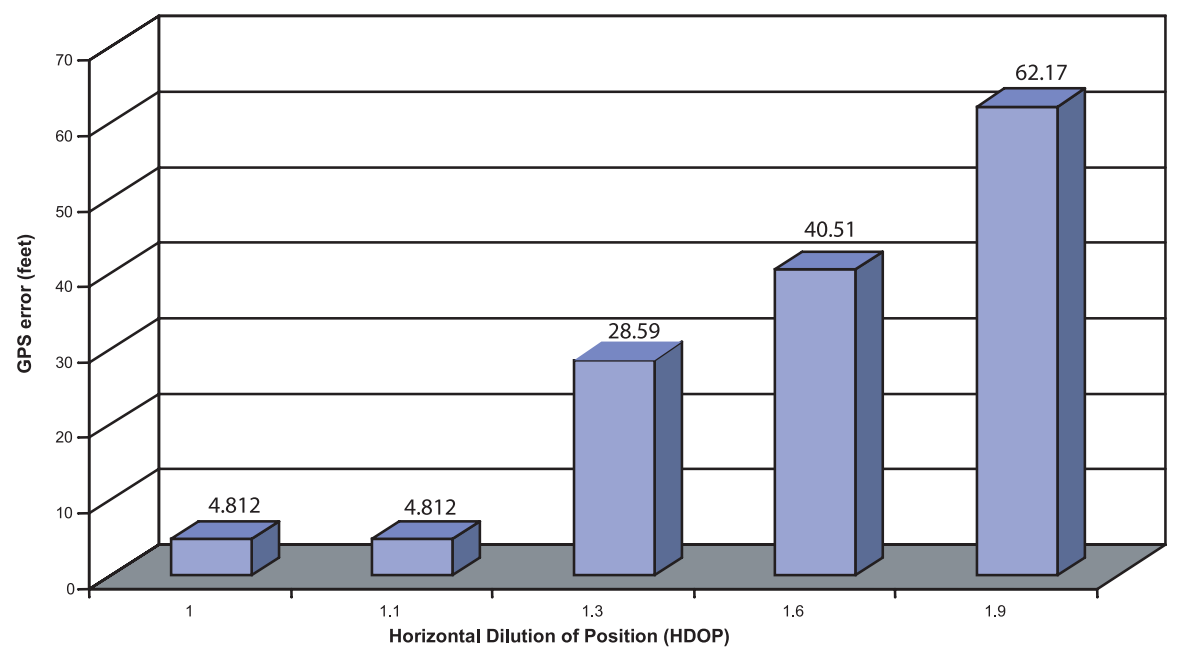




\section{Figure 6: GPS Error Variation by Time - Raw and Filtered GPS Data}

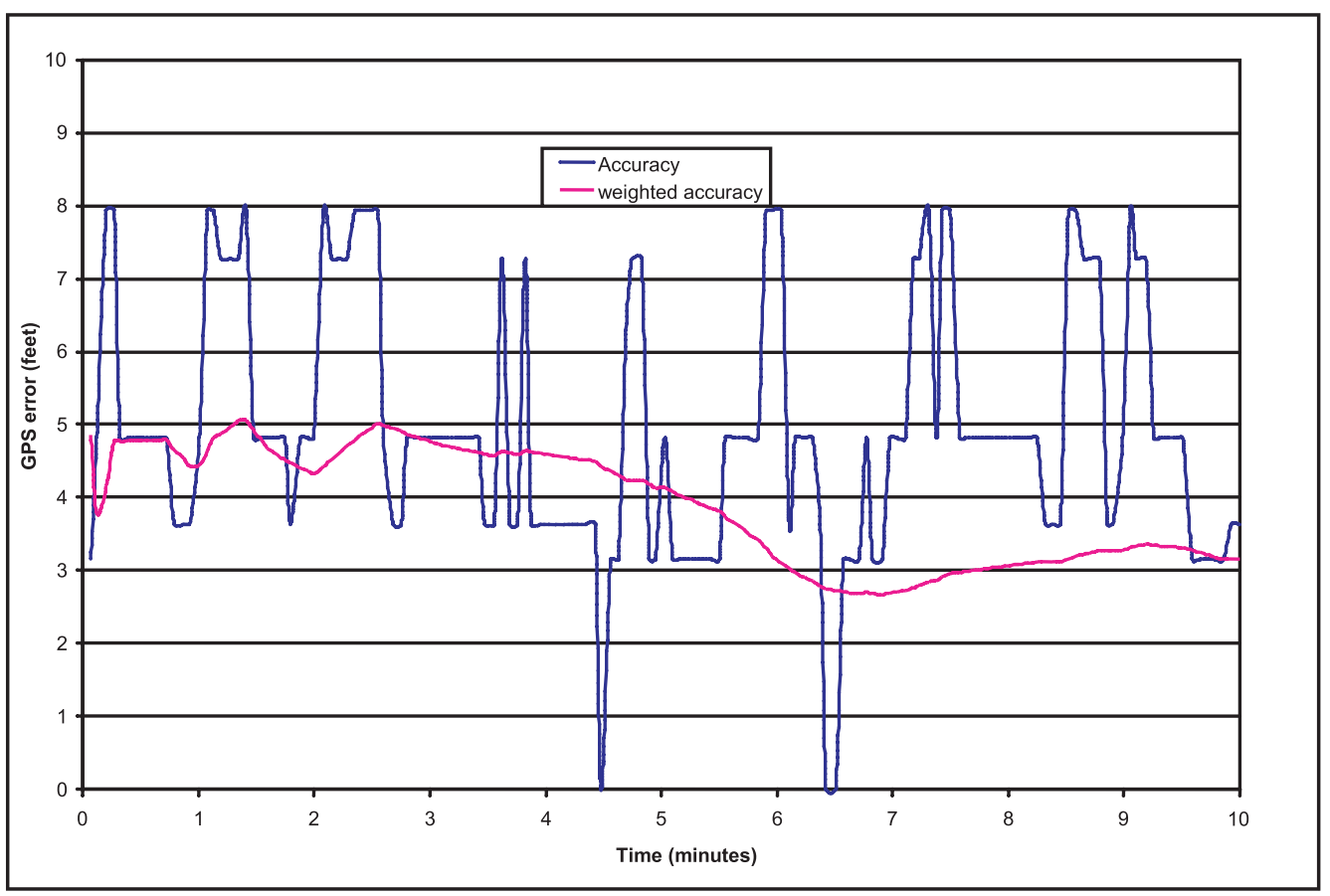

Table 7: Data Filtering Statistical Summary

\begin{tabular}{|c|l|c|c|c|}
\hline \multirow{4}{*}{ Accuracy } & GPS orientation & Mean (feet) & Range (ft) & 95 \% CI (ft) \\
\cline { 2 - 5 } & Raw Data & 4.97 & 0 to 9.62 & 4.68 to 5.28 \\
\cline { 2 - 5 } & $\begin{array}{l}\text { Moving weighted average } \\
\text { based on HDOP }\end{array}$ & 3.94 & 2.67 to 9.62 & 3.79 to 4.08 \\
\hline
\end{tabular}

\section{CONCLUSIONS AND RECOMMENDATIONS}

As the use of GPS in crash location continues to increase, there is a great need to understand the factors that might influence its accuracy. This study was conducted to quantify the influence of different factors likely to affect the accuracy of GPS receivers used for collecting crash location. The factors studied included time of the day, GPS orientation, site conditions, number of satellites, and weather. In addition, the procedure that was followed to choose the best GPS receiver for use in crash location in Florida was documented.

The research results showed that the major factors that significantly influence the accuracy of GPS receivers were the GPS orientation and site conditions. The coordinates collected with the GPS receiver oriented vertically were significantly more accurate compared to the coordinates that were collected with the GPS receiver oriented horizontally. As for site conditions, the GPS receivers provided more accurate results when data were collected in open space compared to near a tall building or a tree canopy. The paired t-test yielded the mean differences of $5.00 \mathrm{ft}$ and $23.87 \mathrm{ft}$ for tall building versus open space and tree canopy versus open space measurements, respectively. It is possible that the accuracy distortion caused by a tall building was less than for the tree canopy because of the distance of the tall building from 
the survey marker was greater as compared to the distance from the tree canopy. The results also revealed that cloud cover caused significant accuracy reduction. The study further found that there is a relationship between GPS parameters and positional accuracy. The results indicated an improvement in accuracy as HDOP value decreased. The research further indicated the optimal time of 3.0 minutes for collecting GPS data.

The study did not find any defined trend of the accuracy relationship with time of the day. The relationship between the number of satellites and accuracy could not be distinctly established. However, it was found that the increase in number of satellites for the site located in open space resulted in accuracy improvements. It is worth noting that the study that was conducted by Lemmon and Gerdan (1999) indicated that an increase in the number of satellites made no contribution to the accuracy of real-time kinetic GPS positions.

The results reported are based on data collected using one selected GPS receiver. It should be noted, however, that this study did not consider a number of variables that might influence the accuracy of GPS readings as reported by Lechner and Baumann (2000). The factors include clock errors of the satellites, ephemeris errors, tropospheric conditions, ionospheric conditions, and multipath effects. This is because some of the factors could not be easily controlled. The study also did not consider the effect of taking GPS measurements with the GPS receiver inside the vehicle, a practice most police officers would use when collecting crash location.

Further research is needed to quantify how different levels of each variable affects the accuracy of GPS receivers used for crash location - for example, the distance from a tree canopy or a building and different angles of GPS orientation. Detailed satellite information needs to be collected to determine why the increase in the number of satellites did not result in improved accuracy. The satellite details that could be studied include the signal strength of each satellite, satellite number, and the stability of the signals. It is recommended that this study be repeated to determine the difference in accuracy provided by the latest GPS receivers.

\section{References}

Graettinger, A.J., T.W. Rushing, and J. McFadden. "Evaluation of Inexpensive Global Positioning System Units to Improve Crash Location Data." Transportation Research Record 1746, (2001): 94-101.

GARMIN International, Inc. GPSMAP 76S Owner's Manual and Reference Guide. Kansas, 2002.

Green, E.R. and K.R. Agent. Evaluation of the Accuracy of GPS as a Method of Locating Traffic Collisions. Kentucky Transportation Center, Lexington, KY. Research Report KTC-04-08/SPR 276-04-1F. June 2004.

Lechner, W. and S. Baumann. "Global Navigation Satellite Systems." Computers and Electronics in Agriculture 25, (2000): 67-85.

Lemmon, R.T. and G.P. Gerdan. "The Influence of the Number of Satellites on the Accuracy of RTK GPS Positions." The Austrian Surveyor 44 (1), (1999):64-70.

Sando, T., R. Mussa, J. Sobanjo, and L. Spainhour. GPS Usability in Crash Location. Presented at the $74^{\text {th }}$ Annual Meeting of the Institute of Transportation Engineers, Orlando, Florida, 2004. 
Thobias Sando is a Ph.D. candidate at Florida State University. Sando is involved in a research entitled "Implementation of GIS for Crash Data Management." His research interests include the use of pattern recognition techniques and GIS in crash modeling. Sando also performs research on the usability of GPS receivers for collecting field crash data.

Renatus Mussa is an associate professor and director of Traffic Engineering Laboratory at the FAMU-FSU College of Engineering. Mussa has been teaching with the department of civil and environmental engineering of the FAMU-FSU College of Engineering since 1998. He has excelled in research in different areas of transportation engineering including intelligent transportation systems, highway safety and traffic studies.

John Sobanjo is an associate professor at the FAMU-FSU College of Engineering. His research areas of interest include infrastructure management, implementation of new technology in highway applications, construction management, and highway safety. Sobanjo has vast industrial experience gained from working with the California Department of Transportation (CALTRANS) and Texas State Department of Highways and Public Transportation (TxDOT).

Lisa Spainhour is an associate professor at the FAMU-FSU College of Engineering. Her research interests include field performance of roadside barriers, civil engineering applications of composite materials, and engineering data modeling and management. 